\title{
AVALIAÇÃO DA QUALIDADE MICROBIOLÓGICA DE MAQUIAGENS DE USO COLETIVO
}

\author{
Airyne de Souza Benvenutti \\ Andressa Veiga ${ }^{1}$ \\ Luciane Silvia Rossa ${ }^{1}$ \\ Fábio Seigi Murakami ${ }^{*}$
}

BENVENUTTI, A. de S.; VEIGA, A.; ROSSA, L. S.; MURAKAMI, F. S. Avaliação da qualidade microbiológica de maquiagens de uso coletivo. Arq. Cienc. Saúde UNIPAR, Umuarama, v. 20, n. 3, p, 159-163, set./dez. 2016.

\begin{abstract}
RESUMO: O mercado de cosméticos destaca-se no Brasil por apresentar crescimento mesmo diante da crise econômica. Devido ao constante aumento na utilização desses produtos é necessário avaliar a segurança microbiológica, especialmente para produtos de uso coletivo e, portanto, com maior risco de contaminação. O objetivo do presente trabalho foi avaliar a qualidade microbiológica de amostras de cosméticos para maquiagem, de uso coletivo, da cidade de Curitiba, Paraná. Foram analisadas quinze (15) amostras coletadas durante o período de janeiro a agosto de 2015. As análises microbiológicas foram realizadas segundo o Guia ABC de Microbiologia, objetivando a contagem de microrganismos viáveis totais e a pesquisa de patógenos. Quanto à contagem de microrganismos todas as amostras encontram-se dentro dos limites especificados pela legislação vigente. No entanto, três amostras apresentaram contaminação por microrganismo patogênico Staphylococcus coagulase positiva. Em indivíduos adultos saudáveis a utilização de cosméticos contaminados pode não representar sérios riscos, a menos que o organismo seja um patogênico primário, não sendo o caso do gênero Staphylococcus. Entretanto, pode representar perigo para pessoas com sistema imunológico fragilizado. Sendo assim, os conservantes utilizados para as preparações cosméticas permanecem eficazes mesmo após o seu uso coletivo, não apresentando sérios riscos a indivíduos adultos saudáveis.
\end{abstract}

PALAVRAS-CHAVE: Avaliação Microbiológica; Cosméticos; Maquiagem; Uso coletivo.

\section{MICROBIOLOGICAL QUALITY EVALUATION OF PUBLIC USE MAKEUP}

ABSTRACT: The Brazilian cosmetics industry continues to grow despite the country's economic crisis. Due to the increasing use of these products, there is the need to evaluate their microbiological safety, especially for cosmetics of shared use regarding the risk of contamination. The aim of this study was to evaluate the microbiological quality of shared makeup samples in the city of Curitiba - Parana, Brazil. Fifteen samples were collected from January to August 2015. The microbiological investigation was performed according to ABC Microbiology Guide aiming at the total viable microorganism and pathogen count. Regarding the microorganism count, all samples were within the limits specified by law. However, tree samples were contaminated by positive coagulase Staphylococcus. This can pose danger to people with weakened immune systems. Thus, it can be concluded that the preservatives used in the preparation of cosmetics remain effective even after their shared use, and therefore, they do not present serious risk to healthy adults.

KEYWORDS: Cosmetics. Makeup. Microbiological analysis. Shared use.

\section{Introdução}

Os cosméticos são produtos para uso externo, de origem sintética ou natural, destinados à proteção ou embelezamento das diferentes partes do corpo (BRASIL, 2010; BRASIL, 2005), dentre estes produtos, encontram-se os destinados à maquiagem, como, por exemplo, batons, sombras, máscaras para cílios, pós-faciais, e outros.

A história do homem e dos cosméticos se liga desde a Antiguidade com os egípcios, que faziam uso da henna e do khol, e com os gregos, que possuíam hábitos de higiene e procedimentos com utilização de cosméticos (TREVISAN, 2011; CRF-PR, 2010). Atualmente, a cada ano o setor de cosméticos tem registrado aumento significativo como demonstram os dados da Associação Brasileira da Indústria de Higiene Pessoal, Perfumaria e Cosméticos (ABIHPEC), os quais indicam que a balança comercial dos produtos de Higiene Pessoal, Perfumaria e Cosméticos nos últimos dez anos, demonstrou um crescimento médio de 7,5\% a.a. nas exportações, e de 19,5\% a.a. nas importações entre 2004 e 2014 (ABIHPEC, 2015).

Para acompanhar esse crescimento, é necessário o emprego de normas de fabricação dos produtos cosméticos, no sentido de "organizar e seguir a produção dos mesmos de forma segura", conforme estabelecido na RDC n 48 de 25 de outubro de 2013, do Ministério da Saúde, a qual enfatiza a importância do cumprimento do Manual de Boas Práticas de Fabricação para produtos de Higiene Pessoal, Cosméticos e Perfumes. Para tal, é imprescindível assegurar a proteção microbiológica, e assim permitir que o produto esteja livre de micro-organismos que possam causar danos à saúde humana, uma vez que isto é de amplo interesse dos consumidores e de órgãos fiscalizadores (SIQUEIRA, 2005; PINTO; KANEKO; PINTO, 2010).

A fim de minimizar os riscos microbiológicos, uma etapa importante do processo de desenvolvimento de um cosmético é a escolha dos conservantes (SIQUEIRA, 2005). Levando em consideração que as características essenciais de qualidade esperadas pelo consumidor vão, desde a eficácia cosmética até a segurança do produto, sendo indispensável a investigação de microrganismos patogênicos, tendo em vista que estes contaminantes podem estar presentes na matéria prima, nos equipamentos, no ambiente de produção, nos operadores e até mesmo nos materiais de embalagem (PINTO, KANEKO; PINTO, 2010).

A agência americana Food and Drug Administration, alerta quanto aos riscos de compartilhar ou trocar os cosméticos com outras pessoas, principalmente as maquia-

DOI: https://doi.org/10.25110/arqsaude.v20i3.2016.5701

${ }^{1}$ Departamento de Farmácia - Laboratório de Controle de Qualidade II - Universidade Federal do Paraná (UFPR) - Curitiba - PR

*Autor para correspondência: Prof. Dr. Fábio Seigi Murakami. Departamento de Farmácia - Laboratório de Controle de Qualidade II - Universidade Federal do Paraná, Av. Pref. Lothário Meissner, 32, Jardim Botânico, 80210-170, Curitiba - PR. E-mail: fsmurakami@gmail.com 
gens, pois o risco de contaminação pode ser ainda maior com os "testadores" em lojas de varejo, onde várias pessoas utilizam a mesma amostra do produto (FDA, 2014) levando em consideração que apesar da existência de cuidados para a fabricação de cosméticos seguros, há pouca informação sobre a eficácia do sistema conservante após condições de uso (TRAN; HITCHINS, 1994).

Estas informações poderiam ser obtidas por meio do Challenge test, o qual pode ser utilizado como ferramenta para predizer a eficácia ou não do sistema conservante após o uso por consumidores. No entanto deve-se também avaliar a embalagem de acondicionamento, a qual pode promover a proteção ou desproteção do produto a possíveis contaminações provenientes do usuário ou do próprio ambiente (BRANNAN; DILLE; KAUFMAN, 1987).

Diante deste contexto, em decorrência de poucos estudos no Brasil sobre a eficácia do sistema conservante após condições de uso, o principal objetivo do presente trabalho foi avaliar a qualidade microbiológica de amostras de cosméticos para maquiagem, de uso coletivo, da cidade de Curitiba, Paraná.

\section{Material e Métodos}

Para este estudo foram selecionados aleatoriamente cosméticos para maquiagem, coletados durante o período de janeiro a agosto do ano de 2015 em farmácias e salões de beleza na cidade de Curitiba- PR. Foram analisadas (15) quinze amostras, sendo elas: duas amostras de sombras; uma amostra de blush; quatro amostras de batons; quatro amostras de máscaras para cílios e quatro amostras de pós faciais.

As metodologias empregadas para os ensaios microbiológicos foram baseadas no Guia ABC de Microbiologia: Controle Microbiológico na Indústria de Produtos de Higiene Pessoal, Cosméticos e Perfumes $3^{\mathrm{a}}$ edição (ABC, 2008).

\section{Análises Microbiológicas}

Todos os materiais utilizados para o processamento das amostras foram previamente esterilizados e os procedimentos microbiológicos foram realizados em fluxo laminar desinfetado de acordo com procedimentos padrões, utilizando etanol a $70 \%(\mathrm{p} / \mathrm{p})$.

O preparo da amostra ocorreu com a diluição desta em diluente universal farmacopeico (BRASIL, 2010), com a finalidade de neutralizar os possíveis conservantes presentes nas amostras, sob agitação mecânica em aparelho stomacher durante 60 segundos.

As amostras de blush, batons e sombras, de mesma marca comercial e coletadas em mesmo local e data foram reunidas a fim de se obter amostra de 10 gramas para que fosse possível a análise quantitativa. E para as amostras de batons, por se tratarem de produtos gordurosos de consistência estável, sendo assim difícil homogeneização, foram fundidos em banho-maria a $32^{\circ} \mathrm{C}$ utilizando $1 / 3$ do volume do diluente e em seguida completou-se com o volume total de diluente à temperatura ambiente.

\section{Análise Quantitativa - Contagem de micro-organismos viáveis totais}

Para contagem de bactérias mesófilas totais, bolores e leveduras foi utilizado o método de semeadura em profundidade, para tanto, foi inoculado $1 \mathrm{~mL}$ da amostra previamente preparada em placa de Petri, e adicionado, separadamente 15-20 mL do ágar adequado para cada contagem.

Foram utilizadas as diluições $10^{-1}$ e $10^{-2}$ preparadas através da diluição com diluente universal e posterior diluição de 1:100 com salina estéril, em duplicata. Para bactérias totais, utilizou-se ágar caseína-soja (Merck $($ ), as placas foram incubadas, de forma invertida, a $30-35^{\circ} \mathrm{C}$ durante um período de 3-5 dias. Para os bolores e leveduras, foi utilizado o ágar sabouraud-dextrose (Merck®) e a incubação foi feita, sem inverter as placas, em temperatura de $20-25^{\circ} \mathrm{C}$ por um período de 5-7 dias.

\section{Análise Qualitativa - Pesquisa de patogênicos}

Para a pesquisa de patógenos foi incluída etapa de pré-enriquecimento em caldo caseína-soja (Merck $\left.{ }^{\circledR}\right)$, para qual foram transferidos $10 \mathrm{~mL}$ da diluição $10^{-1}$ da amostra previamente preparada, em $90 \mathrm{~mL}$ do caldo de pré-enriquecimento não seletivo, o qual foi incubado a $30-35{ }^{\circ} \mathrm{C}$ por um período de 18 - 24 horas.

\section{Pesquisa de Staphylococcus aureus}

A partir do caldo de pré-enriquecimento não seletivo, com o auxílio de alças bacteriológicas estéreis de $10 \mu \mathrm{L}$ foi realizado estriamento por esgotamento em ágar manitol-sal (Merck $\left.{ }^{\circledR}\right)$. As placas foram incubadas de forma invertida, durante 48 horas a $30-35^{\circ} \mathrm{C}$.

A confirmação de crescimento sugestivo em ágar manitol-sal foi realizada por meio de avaliação da morfologia por microscopia óptica utilizando a coloração de gram e provas de coagulase, utilizando o teste rápido Staphclin ${ }^{\circledR}$ de aglutinação do látex e o teste de aglutinação com plasma de coelho.

\section{Pesquisa de Coliformes totais e termotolerantes}

A partir do caldo caseína-soja (Merck $\left.{ }^{\circledR}\right)$, fez-se esgotamento em estrias, de uma alçada $(10 \mu \mathrm{L})$ em ágar MacConkey (Merck $\left.{ }^{\circledR}\right)$, o qual foi incubado, de forma invertida, por um período de 48 horas a $30-35^{\circ} \mathrm{C}$.

\section{Pesquisa de Pseudomonas aeruginosa}

A partir do caldo de pré- enriquecimento não seletivo, fez-se por esgotamento em estrias de uma alçada em ágar Cetrimide (Merck $\left.{ }^{\circledR}\right)$, o qual foi incubado, de forma invertida, por um período de 48 horas a $30-35^{\circ} \mathrm{C}$.

\section{Pesquisa de Salmonella sp}

Para pesquisa de Salmonella sp transferiu-se $0,5 \mathrm{~mL}$ do caldo caseína-soja (Merck $\left.{ }^{\circledR}\right)$ para $10 \mathrm{~mL}$ de caldo Selenito-cystina (Merck $\left.{ }^{\circledR}\right)$, caldo de crescimento seletivo, o qual foi incubado durante 42 horas a $30-35^{\circ} \mathrm{C}$. Deste caldo, foram 
semeadas, pelo método de esgotamento em estrias, placas de ágar XLD- Xilose Lisina Desoxicolato (Merck $\left.{ }^{\circledR}\right)$, incubadas de forma invertida, à temperatura de $30-35^{\circ} \mathrm{C}$ durante $24-48$ horas.

\section{Resultados e Discussão}

O controle de qualidade faz parte das Boas Práticas de Fabricação (BPF) referente à amostragem, especificações, ensaios, procedimentos e documentação, além disso, deve estar envolvido em todas as decisões relacionadas à qualidade do produto, não se limitando apenas às operações laboratoriais (BRASIL, 2003).

Para se avaliar a qualidade microbiológica de cosméticos, perfumes e produtos para higiene pessoal é necessário demonstrar a ausência de microrganismos patogênicos que causam risco ao consumidor, além de determinar a carga microbiana viável presente no produto (BRASIL, 1999).

A RDC n ${ }^{\circ}$. 481, de 23 de setembro de 1999 (ANVISA) foi implantada devido à necessidade da criação de padrões microbianos de qualidade e a necessidade de compatibilizar os regulamentos nacionais com os instrumentos harmonizados no âmbito do Mercosul, com o objetivo de aperfeiçoar as ações de controle de produtos sujeitos à Vigilância Sanitária e às ações de proteção ao consumidor. Nela os cosméticos são classificados em dois tipos, I e II. Os produtos do tipo I incluem os de uso infantil, para área dos olhos e os que entram em contato com mucosas. Já os do tipo II são representados pelos demais produtos susceptíveis à contaminação microbiológica.

A investigação microbiológica das 15 amostras de maquiagens, podem ser visualizadas na Tabela 1. A partir dos resultados obtidos, todas as amostras encontram-se dentro dos limites especificados para contagem de micro-organismos aeróbios totais $\left(<5 \times 10^{2} \mathrm{UFC} / \mathrm{g}\right)$ para produtos do tipo I. Entretanto, em relação à pesquisa de patógenos, os resultados demonstraram que a amostra 3 (pó facial), a amostra 11 (máscara para cílios) e a amostra 15 (sombra) apresentaram contaminação por Staphylococcus coagulase positiva, sugestivo para Staphylococcus aureus.

A confirmação das colônias típicas que cresceram no ágar seletivo manitol-sal, foram evidenciadas através de microscopia óptica (cocos gram positivos), teste de coagulase através da aglutinação em látex e confirmação em plasma de coelho. As provas bioquímicas que foram realizadas neste estudo, podem ser observadas na figura 1 .

Tabela 1: Resultados obtidos para as análises microbiológicas das amostras de cosméticos para maquiagem

\begin{tabular}{c|c|c}
\hline Amostra & $\begin{array}{c}\text { Contagem de } \\
\text { microrganismos } \\
\text { aeróbios totais } \\
\text { (UFC/g) }\end{array}$ & $\begin{array}{c}\text { Pesquisa de } \\
\text { Patógenos }\end{array}$ \\
\hline 1- Pó facial & $3,7 \times 102$ & Ausentes \\
\hline 2- Pó facial & $<1,0 \times 10$ & Ausentes \\
\hline 3- Pó facial & $<1,0 \times 10$ & $\begin{array}{c}\text { Presença de } \\
\text { Staphylococcus } \\
\text { Coagulase Positivo }\end{array}$ \\
\hline 4- Pó facial & $<1,0 \times 10$ & Ausentes \\
\hline
\end{tabular}

\begin{tabular}{c|c|c}
\hline 5- Blush & $<1,0 \times 10$ & Ausentes \\
\hline 6- Batom & $<1,0 \times 10$ & Ausentes \\
\hline 7- Batom & $<1,0 \times 10$ & Ausentes \\
\hline 8- Batom & $<1,0 \times 10$ & Ausentes \\
\hline 9- Batom & $<1,0 \times 10$ & Ausentes \\
\hline $\begin{array}{c}\text { 10- Máscara } \\
\text { para cílios }\end{array}$ & $<1,0 \times 10$ & Ausentes \\
\hline $\begin{array}{c}\text { 11- Máscara } \\
\text { para cílios }\end{array}$ & $<1,0 \times 10$ & $\begin{array}{c}\text { Presença de } \\
\text { Coaghylococcus }\end{array}$ \\
\hline $\begin{array}{c}\text { 12- Máscara } \\
\text { para cílios }\end{array}$ & $<1,0 \times 10$ & Ausentes \\
\hline $\begin{array}{c}\text { 13- Máscara } \\
\text { para cílios }\end{array}$ & $<1,0 \times 10$ & Ausentes \\
\hline 14- Sombras & $<1,0 \times 10$ & Ausentes \\
\hline \begin{tabular}{c} 
15- Sombras \\
\hline
\end{tabular} & $4,0 \times 102$ & $\begin{array}{c}\text { Presença de } \\
\text { Coaghylococcus }\end{array}$ \\
\hline
\end{tabular}

Figura 1: Provas de confirmação das colônias típicas em ágar seletivo manitol-sal

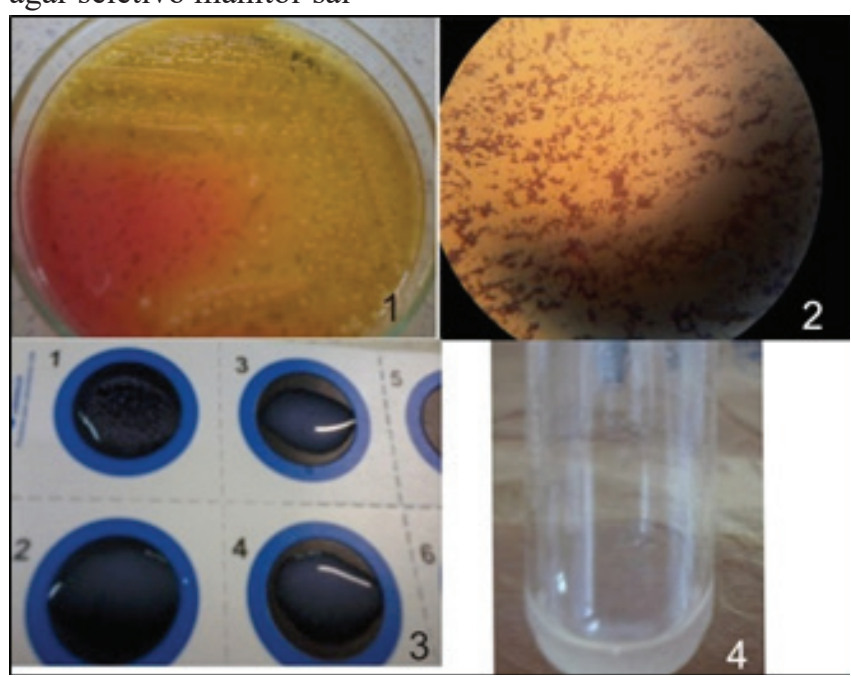

1 - Crescimento em ágar manitol- sal

2 - Morfologia em Microscopia óptica

3 - Teste aglutinação em látex

4 - Prova de coagulase com plasma de coelho

Com os resultados obtidos, avaliando as amostras segundo a RDC n 481/1999, da ANVISA, três amostras foram reprovadas, devido à presença do patógeno Staphylococcus Coagulase Positivo. Estes resultados sugerem que nestes produtos o sistema de conservante utilizado não cumpriu sua finalidade de proteger o produto da contaminação microbiana durante seu uso.

Em estudo realizado nos Estados Unidos da América por Tran \& Hitchins (1994), no qual foram analisadas 2892 amostras de cosméticos para maquiagens, entre eles: máscaras para cílios, sombras, delineadores líquidos, batons, brilhos labiais e blush, foram encontradas contaminação em $50 \%$ das amostras, após enriquecimento. Os autores estimam que apenas $5 \%$ das amostras apresentavam-se com carga microbiana inaceitável, ou seja, elevada em relação às diretrizes da época do estudo, e em apenas $2 \%$ dos produtos analisados, foram isolados patógenos oportunistas, entre eles 
representantes da microbiota normal da pele e contaminantes comuns da água do solo e-ar, como o Staphylococcus aureus e a Pseudomonas aeruginosa, sendo esta isolada em somente $0,07 \%$ das amostras.

Tran; Hitchins (1994) indicam que sejam tomadas medidas para aumentar a segurança dos cosméticos de uso comum, como por exemplo: estipular limites de tempo de uso para os produtos cosméticos testadores de uso compartilhado e promover o uso de dispositivos de amostragem descartável a fim de evitar amostragem com o uso das mãos.

Dawson; Reinhardt (1981), na região de Atlanta, analisaram 1345 amostras de sombras em exposição para clientes, de 15 marcas diferentes, e encontraram contaminação em $67 \%$ das amostras sendo, em sua maior parte, isolados micro-organismos dos gêneros Staphylococcus, $\mathrm{Mi}$ crococcus, Corynebacterium, Acinetobacter, Bacillus, e Moraxella. Estes autores, encontraram Staphylococcus aureus em 2,3 \% das amostras, e não encontraram contaminação por Pseudomonas aeruginosa nem por membros da família Enterobacteriaceae.

Em um estudo realizado para avaliar o crescimento microbiano em 39 máscaras de cílios, sendo que as amostras foram utilizadas diariamente por mulheres num período de 3 meses, foi comprovado o crescimento bacteriano em 12 amostras utilizadas, e isoladas Staphylococcus epidermidis. Diante disso, foi estabelecido que uma substituição de máscaras de cílios a cada três meses deve ser o período recomendado para uso com segurança e as mesmas devem ser descartadas caso haja presença de sintomas de doenças oculares (PACK et al., 2008).

Os produtos que não apresentam alterações sensoriais evidentes podem ser portadores de contaminação microbiana. Em indivíduos adultos saudáveis a utilização de cosméticos contaminados pode não representar sérios riscos, a menos que o organismo seja um patogênico primário. Entretanto pode representar perigo para pessoas com sistema imunológico fragilizado (PINTO; KANEKO; PINTO, 2010).

Dentre os micro-organismos que têm sido isolados em produtos cosméticos encontram-se os chamados patogênicos primários, como a Salmonella sp. e os patogênicos oportunistas a exemplo: Pseudomonas, enterobactérias e espécies de Flavobacterium e Staphylococcus, que se tornam infecciosos quando há fragilidade do sistema imunológico (PINTO; KANEKO; PINTO, 2010).

Vale ressaltar, que a contaminação por Staphylococcus pode ser decorrente do contato dos produtos de maquiagens de uso coletivo diretamente com a pele dos usuários. Tendo em vista que estafilococos, inclusive Staphylococcus aureus podem constituir a flora normal da pele de indivíduos e que a perda de escamas da pele é da ordem de $10^{4}$ escamas por minuto (PINTO, KANEKO; PINTO, 2010).

Ainda é importante verificar que os resultados encontrados podem variar de acordo com o tempo entre a data do uso do cosmético e a data da análise da amostra, pois, de acordo com Tran e Hitchins (1994) é necessário dar tempo ao conservante para que ele possa agir. Portanto, podem ocorrer diferenças entre os resultados obtidos em diversos estudos, tendo em vista que muitas vezes não é possível saber o tempo exato decorrido desde o último uso das amostras de cosméticos não sendo possível afirmar se houve tempo suficiente para a ação do conservante.

\section{Conclusão}

Os cosméticos são produtos não estéreis que podem sofrer contaminação em diversas etapas desde o seu desenvolvimento e produção até sua utilização. Portanto, do ponto de vista microbiológico, os produtos cosméticos para maquiagem, por apresentarem composição complexa, servem como fontes de nutrientes para vários tipos de micro-organismos. A contaminação microbiana é uma das mais estudadas e abordadas, pelo fato de conferir ao produto o potencial risco de causar danos à saúde do consumidor.

No presente trabalho, três amostras apresentaram-se fora dos parâmetros estabelecidos pela RDC n ${ }^{\circ} 481 / 1999$, da ANVISA, devido à confirmação da presença de Staphylococcus coagulase positiva, sugestivo como Staphylococcus aureus.

Este estudo demonstra a importância do controle qualidade de maquiagens e a eficiência dos conservantes utilizados devido ao alto risco de contaminação por microrganismos patogênicos oportunistas.

\section{Referências}

ABC. Guia ABC de Microbiologia: Controle Microbiológico na Indústria de Produtos de Higiene Pessoal, Cosméticos e Perfumes. 3 ed. São Paulo: Pharmabooks, 2008. 59 p.

ABIHPEC. Associação Brasileira da Indústria de Higiene Pessoal, Perfumaria e Cosméticos Panorama do Setor Agosto de 2015. Disponível em:< https://www.abihpec. org.br/novo/wp-content/uploads/2015-PANORAMA-DOSETOR-PORTUGU\%C3\%8AS-11ago2015.pdf > . Acesso em: set. 2015.

BRANNAN, D.K. ; DILLE, J.C. ; KAUFMAN, D.J. Correlation of In Vitro Challenge Testing with Consumer Use Testing for Cosmetic Products. Appl. Environ. Microbiol, v. 53, n. 8, p. 1827-1832, 1987.

BRASIL. Resolução de Diretoria Colegiada n ${ }^{\circ} 481$, de 23 de setembro de 1999. Estabelece os parâmetros de controle microbiológico para os produtos de higiene pessoal, cosméticos e perfumes conforme anexo dessa Resolução. Órgão emissor: ANVISA - Agência Nacional de Vigilância Sanitária

BRASIL. Resolução de Diretoria Colegiada n 210 , de 04 de agosto de 2003. Dispõe sobre regulamento técnico das boas práticas para a fabricação de medicamentos. Órgão emissor: ANVISA - Agência Nacional de Vigilância Sanitária

BRASIL. Resolução de Diretoria Colegiada no 211, de 14 de julho de 2005. Estabelece a definição e a Classificação de Produtos de Higiene Pessoal, Cosméticos e Perfumes, conforme Anexo I e II desta resolução e dá outras definições. Órgão emissor: ANVISA - Agência Nacional de Vigilância Sanitária

BRASIL. Farmacopéia Brasileira 5 ed., v.1, Brasília: 
ANVISA - Agência Nacional de Vigilância Sanitária, 2010.

BRASIL. Resolução de Diretoria Colegiada n ${ }^{\circ}$ 48, de 25 de outubro de 2013. Aprova o Regulamento Técnico de Boas Práticas de Fabricação para Produtos de Higiene Pessoal, Cosméticos e Perfumes, e dá outras providências. Órgão emissor: ANVISA - Agência Nacional de Vigilância Sanitária

CRF-PR. Conselho Regional de Farmácia do Paraná. Guia da Profissão Farmacêutica. Indústria de Higiene Pessoal, Cosméticos e Perfumes. 2010. Disponível em:<http:// www.crf-pr.org.br/uploads/comissao/6295/Guia_cosmetico. pdf $>$. Acesso em: set. 2015.

DAWSON, N.L.; REINHARDT, D.J. Microbial flora of inuse, display eye shadow testers and bacterial challenges of unused eye shadows. Appl. Environ. Microbiol., v. 42, n. 2, p. 297-302, 1981.

FDA. Food and Drug Administration. Product information. 2015. Disponível em: < http://www.fda.gov/ Cosmetics/ProductandIngredientSafety/ProductInformation/ ucm137241.htm> Acesso em: set. 2015.

PACK, LD ET AL. Microbial contamination associated with mascara use: Optometry. J. Amer. Optometric Ass., v. 79, n. 10, p. $587-593,2008$.

PINTO, T.J.A.; KANEKO, T.M.; PINTO, A.F. Controle Biológico de Qualidade de Produtos Farmacêuticos, Correlatos e Cosméticos. São Paulo: Atheneu Editora, 2010. $780 \mathrm{p}$.

SIQUEIRA, VL. Cuidados microbiológicos em cosméticos e produtos de higiene pessoal. Informativo CRQ - IV, Jul. /Ago. 2005.

TRAN, T.T; HITCHINS, A, D. Microbial survey of shareduse cosmetic test kits available to the public. J. Ind.

Microbiology. v.13, p. 389-391, 1994

TREVISAN, C. A. História dos Cosméticos. 2011.

Disponível em: <http://crq4.org.br/?p=texto.php\&c=historia doscosmeticosquimicaviva $>$. Acesso em: set. 2015.

Recebido em: 24/05/2016

Aceito em: 20/09/2016 